\title{
Métodos de avaliação da adesão farmacoterapêutica adotados no Brasil
}

\author{
Methods for evaluation of therapeutic medication \\ adherence adopted in Brazil
}

Silvana Cristina TRAUTHMAN, Marcela Ferro BIUDES, Alexandra Ferro de MELLO, Fernanda Santana ROSA, Carla Antunes PETERS, Dayani GALATO

Programa de Pós-Graduação em Ciências da Saúde - Universidade do Sul de Santa Catarina - Avenida José Acácio Moreira, 787, Dehon, Tubarão-SC. CEP 88704900; Telefone 048 36213363.E-mail: dayani.galato@gmail.com

\begin{abstract}
One of the biggest challenges for the rational use of medicines is the promotion of adherence and therefore there is a need to evaluate such factor. The main goal of this review was identify the methods used to evaluate the pharmacotherapy adherence adopted in Brazil. For this purpose a search was carried out at SCIELO, MEDLINE e BVS databases, for the keywords adherence to treatment, adherence to medication, medicine, psychometrics and Brazil. On this research 542 papers were selected and after screening those that did not present relevance for the investigated subject (adherence evaluation), resulting in 67 studies. The investigation of adherence in Brasil was increased mainly from the year 2000. Cross-sectional study was the most commonly found as well adults as subjects. The mainly investigated diseases were Aids and tuberculosis. The most commonly found research was about investigations on medication at a period of time. These results indicate that the study of adherence in Brazil began in the last decade, specially used for infectious diseases investigation, mainly through indirect methods of measurement. Also, pointed to a lack of method standardization when assessing adherence considering the specific therapeutic demanded by different diseases.
\end{abstract}

KEY WORDS: medication compliance; medication adherence; drugs; Brazil

\section{RESUMO}

Um dos maiores desafios para a promoção do uso racional de medicamentos é a promoção da adesão e, portanto, há a necessidade de avaliação deste comportamento. Com o objetivo de identificar os métodos utilizados para medir a adesão terapêutica no Brasil, foi realizada uma revisão bibliográfica narrativa. Pesquisou-se nas bases SCIELO, MEDLINE e BVS adotando-se os descritores: adesão ao tratamento, adesão à medicação, medicamento, Brasil e psicometria e suas respectivas traduções em inglês e espanhol. Foram localizados 542 trabalhos, excluídos os repetidos, aqueles que não avaliavam a adesão e os artigos de revisão, foram selecionados 67 trabalhos. A investigação da adesão ganhou destaque no país, principalmente, a partir do ano 2000. As doenças mais investigadas foram a Aids e tuberculose. O tipo de estudo mais adotado foi o transversal, geralmente investigando pacientes adultos. Foram encontradas 16 diferentes métodos de medida, dos quais os mais frequentes foram os instrumentos de medida de adesão e os inquéritos sobre a administração de medicamento em um determinado período. Estes resultados apontam que o estudo da adesão terapêutica no Brasil é recente, sendo verificada a utilização, principalmente nas doenças infecciosas e através de técnicas indiretas de medida. É observada a falta de padronização na avaliação da adesão considerando as especificidades terapêuticas demandadas pelas diferentes doenças.

PALAVRAS-CHAVE: adesão ao tratamento farmacológico; adesão à medicação; medicamento; Brasil. 


\section{INTRODUÇÃO}

A adesão à medicação é um dos fatores primordiais no contexto do Uso Racional de Medicamentos. Segundo a Organização Mundial da Saúde (OMS), a adesão é o grau em que o paciente segue as instruções do prescritor (1). A adesão ao tratamento é influenciada por fatores relacionados com a terapêutica, a compreensão, a adaptação e a aceitação de suas condições de saúde (2)e a relação com a equipe de saúde, em especial a confiança no prescritor (3). No entanto, é frequente transferir unicamente aos pacientes a responsabilidade por falhas na adesão (4).

Existem várias formas de medida da adesão terapêutica que podem ser diretas, como a determinação da dosagem plasmática $(5,6)$ ou urinária $(6)$, determinando a presença ou até quantificando o medicamento ou seu metabólito. No entanto, as formas mais frequentes são as verificações indiretas, geralmente medidas por contagem de comprimidos $(5,6,7)$, resposta clínica $(5,6,7)$, acompanhamento do registro de dispensação (7), reabastecimento de comprimidos $(6,7)$, acompanhamento eletrônico do tratamento medicamentoso $(6,7)$, autorrelato do paciente $(5,7)$, entrevistas ao paciente com testes ou escalas de auto percepção de adesão $(5,6)$ e percepção do médico ou profissionais de saúde $(5,7)$. Para Polejack e Saidl (2010) todas estas formas de medida de adesão podem ser consideradas métodos de verificação de adesão (7).

Através das formas diretas, considera-se possível monitorar a ingestão dos medicamentos pelo paciente, embora o mesmo esteja sujeito a algumas variações por motivos alheios à adesão farmacoterapêutica (7) como, por exemplo, pela alteração na extensão da absorção, na metabolização e na excreção (6). E ainda, há que se considerar os interferentes da fase analítica de determinação do parâmetro objeto de monitoramento, a dificuldade de obtenção da amostra, os custos e a disponibilidade dos testes.

Em relação às formas indiretas, existe a restrição da não comprovação da ingestão do medicamento pelo paciente e da superestimação de adesão. No entanto, essa forma oferece vantagens por ser um método cômodo, fácil e de baixo custo de ser aplicado (6).

Existem dificuldades em se avaliar a adesão (5), oque é confirmado pela inexistência de um método de medida considerado "padrão ouro" $(7,8,9,10)$, bem como pela disponibilidade de uma variedade de metodologias empregadas, as quais têm sido adotadas de modo isolado ou associadas $(3,11)$. Na busca de maior veracidade na avaliação, alguns autores defendem a associação de mais de um método $(7,8,9,10)$.

A avaliação da adesão torna-se importante uma vez que a falha terapêutica pode determinar a falência do tratamento (12) e, consequentemente, o aumento da morbidade, da mortalidade e dos custos do sistema de saúde. Considerando o contexto apresentado, este trabalho tem por objetivo identificar os métodos utilizados para a determinação da adesão farmacoterapêutica adotados no Brasil através de uma revisão de literatura, bem como, a definição de parâmetros de adesão utilizados.

\section{MATERIAL E MÉTODOS}

Trata-se de revisão da literatura sobre o tema métodos de verificação da adesão farmacoterapêutica adotados no Brasil. Nesta pesquisa foram considerados métodos de verificação de adesão todas as formas de medida de adesão, como já adotado em revisão sobre o tema (7).

A busca de trabalhos científicos se deu através da exploração dos seguintes bancos de dados U.S. National Library of Medicine's ${ }^{\circledR}$ (MEDLINE), Biblioteca Virtual em Saúde (BVS) e Scientific Electronic Library Online (SCIELO).

Tendo como meta a identificação dos tipos de métodos adotados no Brasil para a determinação da adesão farmacoterapêutica, foi elaborada uma estratégia de busca nas bases de dados utilizando os seguintes descritores em diversas combinações: adesão ao tratamento, compliance and treatment adherence, cumplimiento de la medicación; adesão à medicação, medication adherence, cumplimiento de la medicación; medicamento, drugs, medicamentos; Brasil, Brazil; psicometria, psychometric, psicometría. Entre os descritores foi selecionado psicometria, para possibilitar a identificação de pesquisas que envolvessem o desenvolvimento e validação de instrumentos para a medida de adesão. Destaca-se que foram adotados os mesmos descritores e combinações em todas as bases.

Os critérios de inclusão dos trabalhos foram: ter sido encontrado pela estratégia elaborada, publicado no período delimitado (01 de janeiro de 1990 a 08 de maio de 2011) e; estar publicado nos idiomas português, espanhol ou inglês. E, como critérios de exclusão: ser uma revisão sobre o tema; não ter sido realizado no Brasil e não utilizar métodos para avaliação da adesão. Estes critérios foram adotados em todas as etapas de análise. Salienta-se que na terceira etapa além dos dois critérios já mencionados foram excluídos trabalhos que não se apresentavam na forma de texto completo.

Na busca, foi localizado um total de 542 trabalhos; em seguida foi realizada uma triagem para a exclusão dos artigos repetidos, ou seja, quando o mesmo trabalho foi localizado em mais de uma base ou por mais de uma combinação de descritores, o que reduziu para 215 trabalhos. 
Posteriormente, por consenso entre os proponentes da pesquisa, foram aplicados os critérios de exclusão: na primeira etapa foram analisados apenas os títulos; na segunda, os resumos; na terceira, a leitura dos textos completos. Na última etapa, os pesquisadores formaram duas equipes de leitura e elegeram por consenso 67 artigos. No caso de discordância, em alguma etapa da pesquisa, o material permanecia para apreciação na próxima etapa do processo de análise. Neste caso, a próxima etapa foi definida com base no esquema apresentado na Figura 1, o qual apresenta o detalhamento das etapas de seleção dos trabalhos. Quando não houve consenso na leitura do resumo, o mesmo foi lido na íntegra e analisada a pertinência de inclusão na revisão.

Figura 1. Esquema de seleção dos trabalhos identificados.

\section{Bases de dados: BVS, MEDLINE, SCIELO}

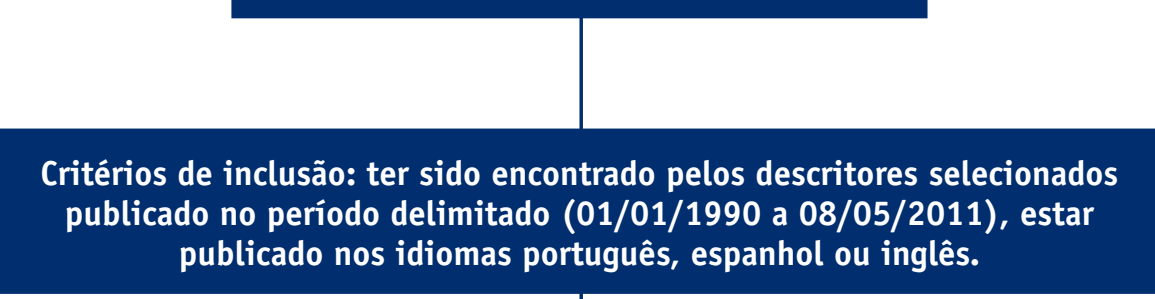

327 Eliminados por repetição

\section{Artigos identificados}

215 Artigos potencialmente relevantes

77 Excluídos após análise dos títulos*

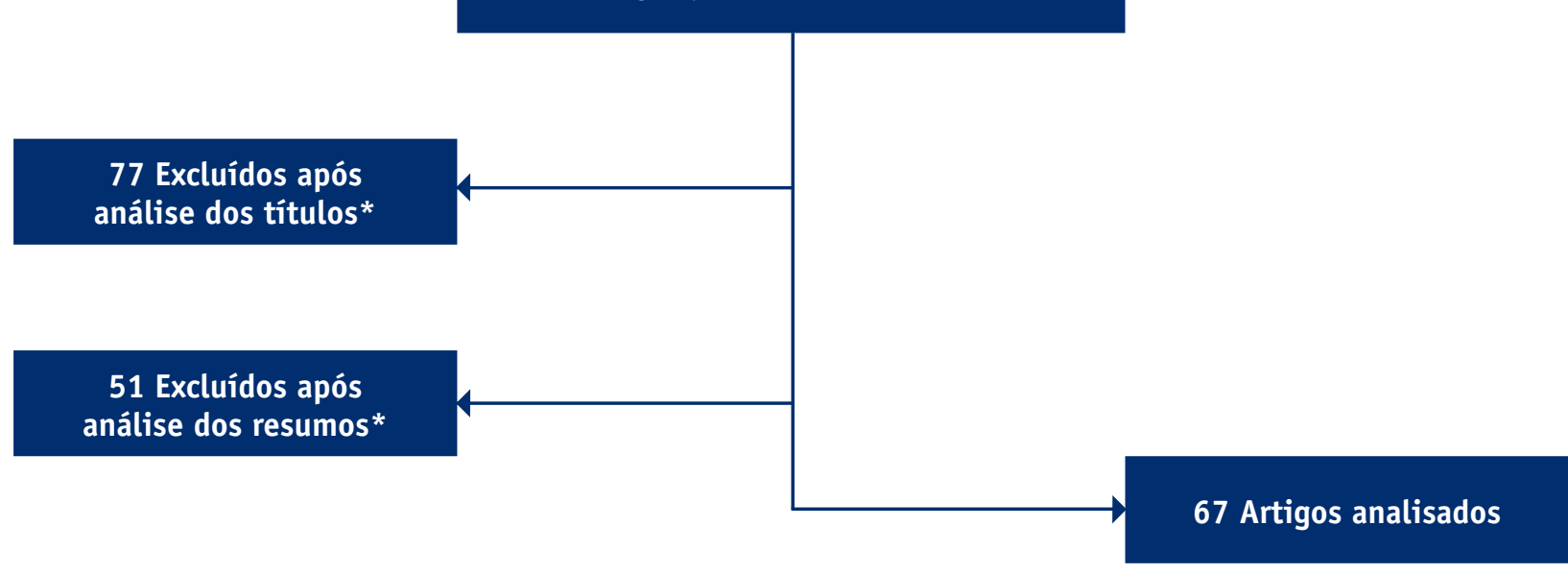

* Ter sido publicado apenas na forma de resumo, ser uma revisão sobre o tema, não ter sido realizado no Brasil ou não utilizar métodos para avaliação da adesão.

$\lceil$ Não estar disponível na forma de texto completo. 
Devido ao grande número de métodos utilizados para a avaliação da adesão, e pela diversidade de termos descritos na literatura, para que fosse possível a sistematização das informações foi realizada inicialmente uma organização dos métodos através da forma adotada para aferição da adesão tendo como base informações já publicadas $(6,7)$.

Os tipos de métodos de verificação identificados e sua descrição estão apresentados no Quadro 1. É importante destacar que o método de avaliação da adesão a "Percepção do profissional de saúde ou cuidador"; foi adotado para identificar os pacientes como como aderentes e não aderentes, sendo o mesmo quantificado. Os resultados foram organizados por meio dos tipos de métodos adotados, identificando os tipos de estudo, local de realização do estudo, os sujeitos investigados e as doenças presentes nestes sujeitos, o método de avaliação de adesão empregado e a definição de adesão. Como definição de adesão nesta pesquisa foram considerados os critérios adotados pelos diferentes autores dos trabalhos para caracterizar o paciente como aderente.

\section{RESULTADOS}

Todos os trabalhos selecionados organizados por tipo de método estão apresentados no Quadro 2. No Quadro 3 está descrito o problema de saúde investigado, a população investigada, o ano de publicação, o tipo de estudo e a região do país em que foi desenvolvido.

O mais antigo trabalho identificado foi de 1996 (61); a maioria dos trabalhos de avaliação da terapia farmacológica foi publicada a partir de 2000 , sendo mais frequentes a partir de 2007 (8,9,12-60,62-77). Dos trabalhos avaliados, em torno de um terço tinha como objetivo a medida de adesão aos medicamentos em pacientes que vivem com HIV/Aids $(8,9,12-24,26,27,32,35,37,55,65$ 68), seguidos dos estudos que abordavam pacientes portadores de tuberculose $(34,38,54,56,69,70,75-77)$, e aqueles com hipertensão arterial sistêmica (3,9$42,59,60,64,71)$. Dentre os demais se têm aqueles realizados com portadores de doenças do coração e diabetes mellitus como os mais frequentes $(25,28-31,33,35,43$ $52,57,58,61-63,72-74)$.

Os tipos de estudo epidemiológicos mais adotados para a avaliação da adesão foram os transversais e de coortes $(8,9,12-22,25,28-30,32-36,38-52,54-58,60-71,73-77)$.

Quanto à população para as quais os estudos foram orientados, constatou-se que a grande maioria dos trabalhos incluía pacientes adultos $(8,9,12-22,24-32,34-$ $39,41,42,45-47,50-52,54-62,64-70,72-77)$.

Considerando todos os estudos revisados, independente da doença estudada, pode se observar o emprego de 16 métodos diferentes, para se medir a adesão ao tratamento, sendo que em alguns estudos adotou-se mais de uma forma de aferição da adesão. Teve destaque o emprego dos instrumentos de medida de adesão como questionários e entres estes o teste de Morisky (25,39$41,43,46,48,51,62)$ foi o mais utilizado. Também foram bastante utilizados os inquéritos sobre a administração de medicamento em um determinado período $(8,12-31)$, observando-se diferentes tempos de recordatório.

Os métodos menos utilizados foram o dispositivo eletrônico (67), com finalidade de monitorar a abertura do frasco e o horário de administração, e o registro periódico das tomadas, como a adoção de diários (56).

Foi observado apenas um trabalho utilizando métodos diretos para a verificação da adesão (30). Isto provavelmente está relacionado com a complexidade desta forma de aferição, que necessita, por exemplo, de um laboratório para realização as análises, bem como, de recursos financeiros mais expressivos que outros métodos indiretos.

Outro resultado observado foi que independentemente do método utilizado muitos autores $(25,28,38,40,44,52,55,59,60,63)$ não deixam claro qual a definição de parâmetro de adesão utilizado em pelo menos um dos métodos adotados, sendo possível apenas observar quais os métodos utilizados. Quanto à verificação da definição de parâmetros de adesão por dose esquecida foi observada valores distintos para um mesmo tratamento, como é o caso da Aids cujos parâmetros vaiaram de $\geq 80$ a $\geq 95 \%(8,12-24,26,27)$.

\section{DISCUSSÃO}

Nesta revisão foi observado um recente incremento no número de estudos, notadamente após a publicação da OMS (3) de 2003 que expõe a necessidade de conhecer sobre a adesão aos tratamentos. Além disso, há diretrizes no SUS que priorizam o tratamento de doenças infecciosas como o HIV e a tuberculose $(12,82,84)$, o que pode explicar a maior proporção de estudos de avaliação da adesão referentes a estes problemas de saúde.

Verificou-se que estudos com crianças ocorreram com menor frequência, sendo observado em especial entre portadores do vírus HIV e de tuberculose. Uma explicação para isso é que as crianças possuem autonomia limitada, e neste caso, a adesão é entendida como cuidado. Outro fato que contribui para esta dificuldade pode estar relacionado com questões que dificultam a investigação, como por exemplo, a necessidade da autorização dos pais ou cuidadores. Dessa forma, o pesquisador depende da disponibilidade destes em participar da pesquisa, bem como, da capacidade dos mesmos em relatar a rotina da criança. Isto pode ocorrer por estresse, por aspectos cognitivos e pelo próprio relacionamento entre o adulto responsável e a criança (78). 
Quadro 1. Descrição da sistematização dos métodos identificados para avaliação da adesão à medicação no Brasil no período investigado.

Avaliação de adesão

Inquérito sobre a administração de medicamentos em um determinado período

Registro de dispensação de medicamentos da farmácia

Aplicação de instrumentos de medida de adesão

Comparecimento ao serviço

Contagem de doses

Autorrelato

Escala da percepção de adesão pelo paciente

Percepção do profissional de saúde ou cuidador

Parâmetro clínico e laboratorial

Dispositivo eletrônico de verificação da adesão

Análise de prontuário do paciente

Tipo de encerramento

Taxa de adesão

Atuarial

Registro periódico das tomadas

Método direto

\section{Descrição}

Situação onde é obtida do usuário a informação do número de doses que o paciente fez uso em um intervalo de tempo definido pelo pesquisador.

Verificação através das datas de retiradas e do número de medicamentos fornecido para o período observado.

Perguntas destinadas à verificação da adesão, podendo em alguns casos obter inclusive informações dos motivos de não adesão. 0 conjunto das respostas define o paciente como aderente ou não.

É analisada a frequência de comparecimento do paciente ao serviço.

É a contagem no número de doses consumidas, comparando-a com o que de fato deveria ter sido consumida no período considerado.

Informação obtida do paciente sobre sua autopercepção em ser aderente sem o uso de qualquer instrumento ou escala.

Definição da extensão da adesão feita pelo paciente frente a uma escala que expressa à intensidade de adesão.

Pela percepção de adesão feita pelo profissional ou cuidador.

Avaliação da adesão considerando parâmetros clínicos. Exemplos: níveis pressóricos, carga viral, CD4, baciloscopia e cultura.

Monitoramento da abertura do frasco e do horário de uso dos medicamentos por dispositivo eletrônico acoplado ao frasco de medicamento.

Para verificação de adesão e abandono, no caso, é analisado a presença de registro indicando a adesão ou não adesão.

Avaliada pela verificação da forma de realização do tratamento e desfecho clínico, considerando a cura, o abandono, a falência ou óbito.

Verificada através da taxa de cura comprovada e não comprovada, falência, casos incidente e retratamento.

Técnica de análise de sobrevida ou tábua de sobrevida.

É um registro das doses tomadas em um formulário especifico, pelo paciente ou observador. A análise deste documento definirá a adesão do paciente ao tratamento.

Por dosagem do medicamento ou metabólito em materiais biológicos como sangue e urina.
Além disso, a medida de adesão é geralmente realizada para o tratamento de doenças crônicas e as crianças representam apenas uma pequena parcela deste grupo.

Nos estudos relacionados ao uso de terapias antirretrovirais, como também nos demais, não existe um método que seja mais adequado $(7,8,9,10)$ para medir a adesão ao tratamento. Como consequência alguns autores utilizam mais de um método para medir a mesma, embora tenha sido mais frequente a utilização de um único método $(9,15-18,20-24,26,32,33,35,36,55,65-68)$. Forgaty e colaboradores (11) realizaram um estudo de revisão sobre a adesão ao tratamento com antirretrovirais e também verificaram a associação de métodos. Estes dados na verdade refletem os esforços para a verificação da adesão a tratamentos contínuos (10), que também devem ser empenhados pelos profissionais que acompanham pacientes em tratamento medicamentoso independente da doença estudada.

Entre os métodos, verificou-se que foram utilizados quase que exclusivamente os indiretos, sendo os instrumentos de medida de adesão como questionários $(13,14,25,27,35-52,62)$ os mais frequentes. Quando se opta pelo uso de instrumentos de medida de adesão, tem sido a escolha para boa parte dos pesquisadores o teste de Morisky (79), da língua inglesa Morisky Medication Adherence Scale-4 items (MMAS-4) (80), originalmente desenvolvido para avaliar a adesão ao tratamento de hipertensão arterial sistêmica, pela avaliação de atitudes relacionadas ao tratamento. Contudo, seu emprego não é condicionado à doença a qual o método foi desenvolvido 
e validado. O instrumento é composto por quatro questões, em que uma resposta positiva ( $\mathrm{sim}$ ) classifica o paciente como não aderente. Como todos os métodos, nem sempre este instrumento tem predito de forma adequada o controle da doença (81). Isso pode estar relacionado ao fato de que o controle da doença não depende exclusivamente da adesão ao medicamento, mas também da efetividade dos medicamentos empregados (10) e da adoção de mudanças do estilo de vida (3). Portanto, a adesão abrange o comportamento do paciente em relação ao seu medicamento e seu problema de saúde (80).

Contudo, mesmo que o teste de Morisky esteja sendo amplamente adotado, inclusive para terapias que o mesmo não tenha sido validado, um estudo recente com pacientes hipertensos demonstrou que inclusive para aferição da adesão em pacientes hipertensos este método se mostrou com baixa sensibilidade e especificidade (81).

A utilização de comparecimento ao serviço como método de avaliação da adesão, amplamente empregado no tratamento da tuberculose pode, como demonstrado por Strelec e colaboradores (82), prestar-se a avaliação da adesão ao tratamento, contudo nem sempre este resultado estará associado ao controle da doença. O emprego de métodos centrados no paciente que abordam a tomada do medicamento pode ser útil nesta situação. É fato, que no caso da tuberculose, o não comparecimento do Serviço é uma prova de não adesão, no entanto, a presença às consultas, aos exames e a retirada dos medicamentos não garantem a adesão farmacoterapêutica. Ainda, relativo ao tratamento da tuberculose, foi observado que não se estabelece como principal intuito a quantificação da adesão limitada ao tratamento farmacológico, mas sim à taxa de cura ou formas de encerramento de tratamento $(34,54,69,75,76)$. O Ministério da Saúde do Brasil preconiza meta de cura maior ou igual a $85,0 \%$ (83), tendo sido este parâmetro adotado pelos estudos, além de medida de abandono, visita regular ao serviço e os resultados da estratégia de observação direta do tratamento (do inglês, Directly Observed Treatment-DOTs).

Nem sempre há associação da adesão farmacoterapêutica à verificação de dados clínicos e laboratoriais do paciente em que se considera, por exemplo, o controle pressórico $(40,59,60)$ e a carga viral indetectável $(37,66)$. Isto pode ocorrer devido a diversos fatores, a exemplo do tratamento do HIV, a divergência entre a adesão e o resultado clínico pode estar relacionada ao desenvolvimento de resistência viral (7).

No entanto, a verificação de adesão pode ser adotada como uma aliada importante na tomada de decisões relacionadas à farmacoterapia. Pois, o clínico poderá lançar mão desta avaliação, pelo emprego de um ou mais métodos de verificação da adesão, na análise dos resul- tados da farmacoterapia do paciente. Esta estimativa sinalizará para a adoção de medidas de incentivo à adesão ou a mudança da estratégia terapêutica para tratamento da doença, de acordo com seus protocolos clínicos, diretrizes e consensos.

O relato de adesão dos pacientes (método indireto) geralmente é superestimado, isto pode ocorrer devido a uma percepção equivocada do que seria adesão, por receio de recriminação, ou mesmo para não decepcionar o profissional da saúde (10). Outro fator que pode superestimar a adesão é o viés de memória que pode interferir nos resultados do recordatório de doses tomadas, ou esquecidas (6).Quanto ao desenho adotado para avaliar a adesão, as coortes podem retratar de modo mais fidedigno a adesão, visto que permitem minimizar vieses como o de memória abordado anteriormente. Além de permitirem observar toda uma evolução dos indivíduos durante o tratamento.

Os parâmetros adotados para os estudos de adesão aos tratamentos têm sido definidos de modo diferente entre as doenças, muitas vezes considerando as consequências da não adesão aos pacientes e aos serviços de saúde. Exemplificando este cuidado, em estudos realizados com pessoas vivendo com HIV, por se tratar de uma situação que exige o estabelecimento de elevados níveis de adesão às terapias antirretrovirais ${ }^{3}$ foi comum nos estudos analisados (12-15,17-20,23,24,26,36,37,67), a verificação do uso de parâmetro de boa adesão estabelecido como igual ou superior a $95,0 \%$, o que também tem sido recomendado pela OMS (3). Já para o tratamento da Hipertensão Arterial Sistêmica alguns autores têm preconizado a adesão ao tratamento farmacológico de pelo menos $80 \%$ do uso de medicamentos prescritos $(40,42)$.

A constatação no aumento do número de publicação nos últimos anos e a diversidade dos métodos empregados para avaliar a adesão à medicação reflete o esforço no sentido de aprimorar a determinação e o conhecimento dos seus determinantes, os quais estão estreitamente relacionados com o uso racional de medicamentos.

Contudo, mesmo que não haja um método de referência para a avaliação da adesão à medicação, os resultados desta pesquisa suscitam uma discussão muito pertinente que seria a falta de padronização. Ou seja, uma vez que a adesão é avaliada para um mesmo problema de saúde com diferentes métodos e definições, torna árdua e talvez inviável a comparação dos dados obtidos. Portanto, seria interessante um esforço no sentido de buscar uma maior uniformidade nos estudos, tanto em relação aos métodos empregados como dos critérios adotados para considerar um paciente aderente ou não aderente, a fim de possibilitar maior compreensão deste fenômeno para os diversos problemas de saúde e da farmacoterapia. 
Além disso, o desenvolvimento e validação de novos instrumentos, bem como, a adaptação transcultural de instrumentos já desenvolvidos devem ser considerados quando da padronização dos métodos a serem adotados no Brasil $(53,81)$.

Obter resultados terapêuticos adequados a partir da utilização dos medicamentos é um dos propósitos elencados na Política Nacional de Medicamentos. Este resultado está vinculado, à ênfase ao uso adequado dos recursos terapêuticos, em especial através do uso racional de medicamentos $(9,84)$. Assim, a adesão deve ser entendida como componente importante para este resultado mesmo que sua avaliação constitua um dos maiores problemas desta área de investigação (80).

Os dados apresentados neste estudo demonstram que especial atenção tem sido dada à verificação da adesão ao tratamento de doenças infecciosas e crônico-degenerativas. Isto suscita a importância na realização de investigações sobre outros problemas de saúde, uma vez que o Sistema Único de Saúde brasileiro disponibiliza atendimento a uma diversidade de problemas de saúde independente de sua cronicidade. Também se destaca a crescente necessidade de investimentos no SUS para o seu funcionamento, em especial na área de medicamentos. A verificação da adesão dos pacientes aos tratamentos pode conduzir a melhorias na eficiência econômica do sistema de saúde $(3,62)$, especialmente em países com menor disponibilidade de recursos (7) como é o caso do Brasil.

Esta pesquisa apresenta como uma limitação a não identificação de estudos relacionados ao tema (adesão à medicação), seja pela estratégia de busca adotada, seja por alguma falha durante o processo de análise dos trabalhos.

\section{CONCLUSÃO}

Este estudo demonstra que, mesmo sendo um comportamento bastante aferido, não há padronização do tipo de método para medida da adesão e nem tão pouco dos critérios adotados. Desta forma, não é possível a comparação de resultados nem mesmo para uma mesma doença.

Verificou-se a pouca utilização dos métodos diretos e, consequentemente, a superestimação da adesão. Ainda, cabe salientar que a falta de estudo em regiões onde os recursos de saúde são mais escassos, como norte e nordeste dificultam também a definição clara da realidade relacionada à adesão à medicação no Brasil.

O estimulo para o emprego de métodos de avaliação da adesão à medicação na prática clínica trarão benefícios aos pacientes e ao serviço de saúde. Também é importante o desenvolvimento de mais estudos de desenvolvimento e validação de métodos. Desta forma, sugere-se uma discussão do Uso Racional do Medicamento voltado para além da seleção dos medicamentos e seu acesso, com vistas a estabelecer estratégias que garantam o uso correto de medicamentos e formas de avaliar a adesão. 
Quadro 2. Descrição dos métodos identificados para avaliação da adesão farmacoterapêutica no Brasil no período investigado.

\begin{tabular}{|c|c|c|c|c|}
\hline $\begin{array}{l}\text { Método para } \\
\text { avaliação de adesão }\end{array}$ & $\begin{array}{l}\text { Trabalhos } \\
\text { encontrados }\end{array}$ & $\begin{array}{c}\text { Problemas } \\
\text { de saúde }\end{array}$ & Definições adotadas para avaliação da adesão & Ref \\
\hline \multirow{20}{*}{$\begin{array}{l}\text { Inquérito sobre a } \\
\text { administração de } \\
\text { medicamentos em um } \\
\text { determinado período }\end{array}$} & 3 & \multirow{10}{*}{ Aids } & $\begin{array}{c}\text { Adoção de quantidade } \geq 95 \% \text { das doses como aderente } \\
\text { a partir de um recordatório de dois dias }\end{array}$ & $13,14,15$ \\
\hline & 1 & & $\begin{array}{c}\text { Adoção de quantidade } \geq 80 \% \text { das doses como aderente } \\
\text { a partir de um recordatório de dois dias }\end{array}$ & 16 \\
\hline & 5 & & $\begin{array}{c}\text { Adoção de quantidade } \geq 95 \% \text { das doses como aderente } \\
\text { a partir de um recordatório de três dias }\end{array}$ & $12,17-20$ \\
\hline & 2 & & $\begin{array}{c}\text { Adoção de quantidade } \geq 90 \% \text { das doses como aderente } \\
\text { a partir de um recordatório de três dias }\end{array}$ & 8,21 \\
\hline & 1 & & $\begin{array}{c}\text { Adoção de quantidade } \geq 80 \% \text { das doses como aderente } \\
\text { a partir de um recordatório de sete dias }\end{array}$ & 22 \\
\hline & 1 & & $\begin{array}{c}\text { Adoção de quantidade } \geq 90 \% \text { das doses como aderente } \\
\text { a partir de um recordatório de sete dias }\end{array}$ & 8 \\
\hline & 3 & & $\begin{array}{c}\text { Adoção de quantidade } \geq 95 \% \text { das doses como aderente } \\
\text { a partir de um recordatório de sete dias }\end{array}$ & $19,23,24$ \\
\hline & 1 & & $\begin{array}{c}\text { Adoção de quantidade } \geq 90 \% \text { das doses como aderente } \\
\text { a partir de um recordatório de quinze dias }\end{array}$ & 8 \\
\hline & 1 & & $\begin{array}{c}\text { Adoção de quantidade entre } 80 \text { e } 95 \% \text { das doses como } \\
\text { aderente avaliando todo o tratamento }\end{array}$ & 26 \\
\hline & 1 & & $\begin{array}{l}\text { Adoção de uma escala de } 0 \text { a } 4 \text { (nunca a sempre esquecer) } \\
\text { considerando as últimas doses, menor escore aderente }\end{array}$ & 27 \\
\hline & 1 & Esquizofrenia & $\begin{array}{c}\text { Adoção de um recordatório de } 30 \text { dias - não definiu } \\
\text { claramente parâmetro para adesão }\end{array}$ & 28 \\
\hline & 1 & HAS e DM & $\begin{array}{c}\text { Adoção de um recordatório de sete dias - não definiu } \\
\text { parâmetro para adesão }\end{array}$ & 25 \\
\hline & 1 & Asma & $\begin{array}{l}\text { Adoção de quantidade }>80 \% \text { das doses avaliada foi } \\
\text { considerado aderente a partir de registro diário ( } 6 \text { meses) }\end{array}$ & 29 \\
\hline & 1 & Anemia & Adoção do uso do medicamento no último dia como aderente & 30 \\
\hline & 1 & Não definido & $\begin{array}{l}\text { Adoção de } 100 \% \text { das doses a partir de um recordatório } \\
\text { de } 15 \text { dias foi considerado como aderente }\end{array}$ & 31 \\
\hline & 1 & Aids & $\begin{array}{l}\text { Considera um atraso na retirada }<20 \% \text { como aderente, } \\
\text { avaliação por cinco meses consecutivos. }\end{array}$ & 32 \\
\hline & 1 & Profilaxia & Considera aderente o não abandono do tratamento & 33 \\
\hline & 1 & HIV & Considera um atraso na retirada $<10 \%$ como aderente & 8 \\
\hline & 1 & Aids & Considera um atraso na retirada $<5 \%$ como aderente & 9,12 \\
\hline & 1 & Tuberculose & $\begin{array}{l}\text { Considera aderente quem completa o tratamento } \\
\text { através da retirada mensal do medicamento }\end{array}$ & 34 \\
\hline
\end{tabular}


Quadro 2 (cont): Descrição dos métodos identificados para avaliação da adesão farmacoterapêutica no Brasil no período investigado.

\begin{tabular}{|c|c|c|c|c|}
\hline $\begin{array}{l}\text { Método para } \\
\text { avaliação de adesão }\end{array}$ & $\begin{array}{l}\text { Trabalhos } \\
\text { encontrados }\end{array}$ & $\begin{array}{l}\text { Problemas } \\
\text { de saúde }\end{array}$ & Definições adotadas para avaliação da adesão & Ref \\
\hline \multirow{22}{*}{$\begin{array}{l}\text { Registro de } \\
\text { dispensação de } \\
\text { medicamentos da } \\
\text { farmácia }\end{array}$} & 2 & Aids & Adoção de um escore, considerando o maior valor para adesão & 13,14 \\
\hline & 1 & Aids & $\begin{array}{l}\text { Adoção de uma escala zero a } 3 \text { (nuca esquecer à } \\
\text { frequentemente esquecer), o menor valor como adesão }\end{array}$ & 27 \\
\hline & 1 & Aids & Adoção de uma escala, a pontuação elevada sugere maior adesão & 35 \\
\hline & 1 & Aids & $\begin{array}{l}\text { Auto eficácia ( } 21 \text { situações) respostas adequadas em } \\
\quad \geq 95 \% \text { das situações é considerado aderente }\end{array}$ & 36 \\
\hline & 1 & Aids & $\begin{array}{l}\text { Adoção de uma escala } 0 \text { a } 4 \text { (não vou tomar a com } \\
\text { certeza vou tomar), maior valor representa adesão }\end{array}$ & 37 \\
\hline & 1 & Tuberculose & Não definiu como aferiu a adesão & 38 \\
\hline & 3 & HAS & Adoção de teste de Morisky (nenhuma resposta positiva -aderente) & $39,40,41$ \\
\hline & 1 & HAS & $\begin{array}{l}\text { Adoção do questionário adaptado do QualiAids -não definiu } \\
\text { os critérios para classificar o paciente aderente }\end{array}$ & 40 \\
\hline & 1 & HAS & $\begin{array}{l}\text { Aplicação do QualiAids - considerando como } \\
\text { aderente o escore } \geq 80 \%\end{array}$ & 42 \\
\hline & 1 & HAS & $\begin{array}{l}\text { Adoção do Questionário de Haynes -Quem refere } \\
\text { dificuldades de tomar a medicação foi não aderente }\end{array}$ & 40 \\
\hline & 1 & DAC & $\begin{array}{l}\text { Adoção do teste de Morisky - } 0 \text { alto grau de adesão; } \\
\text { 1-2 média adesão; } 3 \text { ou } 4 \text { baixa adesão }\end{array}$ & 43 \\
\hline & 1 & Esquizofrenia & $\begin{array}{l}\text { Aplicação de um calendário para avaliar a percepção - } \\
\text { não definiu claramente oque foi considerado aderente }\end{array}$ & 44 \\
\hline & 1 & DGC & $\begin{array}{l}\text { Teste de medida de adesão modificado (MAT) escala } \\
\text { de zero a quatro, escore convertido para adesão. }\end{array}$ & 45 \\
\hline & 1 & Câncer & $\begin{array}{l}\text { Adoção do Teste de Morisky, quando nenhuma } \\
\text { resposta positiva considerou-se aderente. }\end{array}$ & 46 \\
\hline & 1 & DM & $\begin{array}{l}\text { Teste de medida de adesão modificado (MAT) escore } \\
\text { convertido em adere e não adere. }\end{array}$ & 47 \\
\hline & 1 & DM & $\begin{array}{l}\text { Teste de Morisky - (nenhuma resposta positiva - mais } \\
\text { aderente; uma ou mais positivas - menos aderente). }\end{array}$ & 48 \\
\hline & 1 & Epilepsia & $\begin{array}{l}\text { Questionário de qualidade de vida em epilepsia (escore } \\
\text { de zero a 100, quanto maior o escore menor a adesão). } \\
\text { Adoção de escala de oito itens para avaliação da adesão } \\
\text { (MMAS-8) - Classificando-a em baixa, média e alta }\end{array}$ & 49 \\
\hline & 1 & Não definido & $\begin{array}{l}\text { Adoção do Teste de Morisky, considerando } \\
\text { nenhuma resposta positiva como aderente. }\end{array}$ & 50 \\
\hline & 1 & LES & $\begin{array}{l}\text { Adoção do teste de Morisky considerando nenhuma } \\
\text { resposta positiva como aderente. }\end{array}$ & 51 \\
\hline & 1 & HAS e DM & $\begin{array}{l}\text { Adoção de um questionário sobre as dificuldades de realizar o } \\
\text { tratamento - não definiu claramente o critério de adesão. }\end{array}$ & 25 \\
\hline & 1 & $\mathrm{HC}$ & $\begin{array}{l}\text { Adoção do Teste de Morisky - considerando nenhuma } \\
\text { resposta positiva como alto grau de adesão e; uma } \\
\text { ou mais positivas como baixo grau de adesão. }\end{array}$ & 52 \\
\hline & 1 & $\mathrm{DGC}$ & & 62 \\
\hline \multirow{2}{*}{$\begin{array}{l}\text { Aplicação de } \\
\text { instrumentos de } \\
\text { medida de adesão }\end{array}$} & 1 & \multirow[t]{2}{*}{ Tuberculose } & $\begin{array}{l}\text { Considera o comparecimento ao Serviço após } 60 \text { dias do término do } \\
\text { tratamento com diagnóstico de cura como aderente }\end{array}$ & 54 \\
\hline & 1 & & Não apresenta o critério adotado para adesão & 38 \\
\hline
\end{tabular}


Quadro 2 (cont): Descrição dos métodos identificados para avaliação da adesão farmacoterapêutica no Brasil no período investigado.

\begin{tabular}{|c|c|c|c|c|}
\hline $\begin{array}{c}\text { Método para } \\
\text { avaliação de adesão }\end{array}$ & $\begin{array}{l}\text { Trabalhos } \\
\text { encontrados }\end{array}$ & $\begin{array}{l}\text { Problemas } \\
\text { de saúde }\end{array}$ & Definições adotadas para avaliação da adesão & Ref \\
\hline \multirow{8}{*}{$\begin{array}{l}\text { Comparecimento } \\
\text { ao serviço }\end{array}$} & 1 & Profilaxia TV & Não apresenta o critério adotado para adesão & 55 \\
\hline & 1 & Aids & Paciente utilizando quantidade $\geq 95 \%$ das doses como aderente & 37 \\
\hline & 1 & \multirow{2}{*}{ Tuberculose } & Não apresenta o critério adotado para adesão & 38 \\
\hline & 1 & & Paciente com tomada de doses menor é indício de não adesão & 56 \\
\hline & 1 & HAS & Paciente utilizando entre 80 e $120 \%$ como aderente & 40 \\
\hline & 1 & DAC & Paciente utilizando quantidade $\geq 80 \%$ das doses como aderente & 57 \\
\hline & 1 & Asma & Paciente utilizando quantidade $>80 \%$ das doses como aderente & 29 \\
\hline & 1 & $\begin{array}{l}\text { Febre } \\
\text { reumática }\end{array}$ & $\begin{array}{l}\text { Considera a contagem de doses de seis meses de tratamento, } \\
\text { o uso de } 100 \% \text { das doses é aderente }\end{array}$ & 58 \\
\hline \multirow{5}{*}{ Contagem de doses } & 1 & Aids & 0 paciente define-se como aderente ou não aderente & 8 \\
\hline & 2 & HAS & Não definiu claramente o critério adotado & 59,60 \\
\hline & 1 & DAC & $\begin{array}{c}\text { Foi considerado aderente quando o paciente refere tomar } \\
\text { adequadamente sem erros ou abandono }\end{array}$ & 61 \\
\hline & 1 & DGC & $\begin{array}{l}\text { Foi considerado aderente o paciente que relata adequadamente os } \\
\text { nomes e forma de uso dos medicamentos }\end{array}$ & 13 \\
\hline & 1 & DM & Não definiu claramente o critério adotado & 63 \\
\hline \multirow{4}{*}{ Autorrelato } & 1 & \multirow{2}{*}{ Aids } & $\begin{array}{l}\text { Adotou duas escalas uma de zero a } 70 \text {, quanto menor } \\
\text { o valor mais aderente e outra entre zero a } 6 \\
\text { (nunca esquecer a sempre esquecer) }\end{array}$ & 27 \\
\hline & 1 & & $\begin{array}{l}0 \text { paciente considerou a sua adesão a partir das opções } \\
\text { péssima, ruim, regular, boa e muito boa. }\end{array}$ & 19 \\
\hline & 1 & \multirow{2}{*}{ HAS } & $\begin{array}{l}\text { Aderente quando o paciente define a sua adesão }>75 \% \text {, } \\
\text { em uma escala de zero a } 100 \% \text {. }\end{array}$ & 64 \\
\hline & 1 & & $\begin{array}{l}\text { Adoção de uma escala de zero a cinco, sendo que cinco } \\
\text { considera o paciente como aderente }\end{array}$ & 39 \\
\hline \multirow{4}{*}{$\begin{array}{l}\text { Escala da percepção de } \\
\text { adesão pelo paciente }\end{array}$} & 1 & \multirow{2}{*}{ Aids } & $\begin{array}{l}\text { A adesão do paciente foi avaliada a partir da percepção } \\
\text { de profissionais em alta, média e baixa adesão }\end{array}$ & 65 \\
\hline & 1 & & $\begin{array}{l}\text { A adesão foi avaliada a partir da percepção dos cuidadores } \\
\text { em péssima, ruim, regular, boa e muito boa }\end{array}$ & 19 \\
\hline & 1 & HAS & $\begin{array}{l}\text { A adesão foi avaliada a partir da percepção do médico } \\
\text { em uma escala de zero a cinco, sendo cinco aderente }\end{array}$ & 39 \\
\hline & 1 & $\mathrm{AF}$ & $\begin{array}{l}\text { A adesão do paciente foi avaliada a partir da percepção } \\
\text { do médico quanto ao uso do medicamento }\end{array}$ & 30 \\
\hline \multirow{5}{*}{$\begin{array}{l}\text { Percepção do } \\
\text { profissional de saúde } \\
\text { ou cuidador }\end{array}$} & 1 & \multirow{3}{*}{ Aids } & Aderentes os pacientes com carga viral < 400 partículas virais. & 66 \\
\hline & 1 & & Aderentes os pacientes com aumento da contagem de células CD4 & \multirow{2}{*}{37} \\
\hline & 1 & & Aderentes os pacientes com diminuição da carga viral & \\
\hline & 1 & Tuberculose & Aderentes os pacientes com baciloscopia negativa & 56 \\
\hline & 3 & HAS & $\begin{array}{l}\text { Aderentes os pacientes com pressão arterial sistêmica } \\
\qquad<140 / 90 \mathrm{mmHg}\end{array}$ & $40,59,60$ \\
\hline \multirow{2}{*}{$\begin{array}{l}\text { Parâmetro clínico e } \\
\quad \text { laboratorial }\end{array}$} & 1 & \multirow[b]{2}{*}{ Aids } & Aderente os pacientes com número de tomadas $\geq 95 \%$ & \multirow[b]{2}{*}{67} \\
\hline & 1 & & $\begin{array}{l}\text { Aderentes os pacientes com até } 25 \% \text { de variação no horário } \\
\text { prescrito }\end{array}$ & \\
\hline
\end{tabular}


Quadro 2 (cont): Descrição dos métodos identificados para avaliação da adesão farmacoterapêutica no Brasil no período investigado.

\begin{tabular}{|c|c|c|c|c|}
\hline $\begin{array}{l}\text { Método para } \\
\text { avaliação de adesão }\end{array}$ & $\begin{array}{l}\text { Trabalhos } \\
\text { encontrados }\end{array}$ & $\begin{array}{l}\text { Problemas } \\
\text { de saúde }\end{array}$ & Definições adotadas para avaliação da adesão & Ref \\
\hline \multirow{8}{*}{$\begin{array}{c}\text { Dispositivo eletrônico } \\
\text { de verificação da } \\
\text { adesão }\end{array}$} & 1 & Aids & $\begin{array}{l}\text { Foram considerados não aderentes os pacientes para os } \\
\text { quais se identificou de registros de não adesão }\end{array}$ & 12 \\
\hline & 1 & Hepatite C & $\begin{array}{l}\text { Foram considerados não aderentes quando se identificou } \\
\text { abandono do tratamento a mais de } 30 \text { dias }\end{array}$ & 68 \\
\hline & 1 & \multirow{2}{*}{ Tuberculose } & $\begin{array}{l}\text { Foram considerados não aderentes quando se identificou } \\
\text { registro indicativo de não adesão }\end{array}$ & 69 \\
\hline & 1 & & $\begin{array}{l}\text { Foram considerados não aderentes quando se identificou } \\
\text { registro indicativo de não adesão }\end{array}$ & 70 \\
\hline & 2 & HAS & $\begin{array}{l}\text { Foram considerados não aderentes quando se identificou } \\
\text { registro de não adesão ou recusa de tratamento }\end{array}$ & 71 \\
\hline & 1 & DAC & $\begin{array}{l}\text { Foram considerados não aderentes quando se identificou } \\
\text { registro indicativo de não adesão (enfermeiro) }\end{array}$ & 72 \\
\hline & 1 & Asma & $\begin{array}{l}\text { Foram considerados não aderentes quando se identificou } \\
\text { registro indicativo de não adesão }\end{array}$ & 73 \\
\hline & 1 & Alcoolismo & $\begin{array}{c}\text { Foram considerados aderentes os pacientes com registro } \\
\text { de frequência em atividades do Serviço durante os } \\
\text { últimos três meses define aderência }\end{array}$ & 74 \\
\hline $\begin{array}{l}\text { Análise de prontuário } \\
\text { do paciente }\end{array}$ & 1 & Tuberculose & Considera o abandono do tratamento como não aderente & 75 \\
\hline Tipo de encerramento & 1 & Tuberculose & Para valores de taxa de adesão $\geq 85 \%$, considera aderente & 76 \\
\hline Taxa de adesão(*) & 1 & Tuberculose & Para valores de sobrevida $\geq 95 \%$, considera aderente & 77 \\
\hline Atuarial $(* *)$ & 1 & Tuberculose & $\begin{array}{l}\text { A fata de registro das doses tomadas no cartão do tratamento } \\
\text { e referência a reações adversas são indícios de não adesão }\end{array}$ & 56 \\
\hline $\begin{array}{l}\text { Registro periódico } \\
\text { das tomadas }\end{array}$ & 1 & $\mathrm{AF}$ & $\begin{array}{l}\text { Dosagem da atividade antibiótica na urina, quando } \\
\text { adequada o paciente é aderente. }\end{array}$ & 30 \\
\hline Método direto & & & & \\
\hline
\end{tabular}

(*) leva em conta os casos de cura comprovada e não comprovada, de falência, de incidência e retratamento; $(* *)$ - cálculo através da tábua de sobrevida; HAS - Hipertensão Arterial Sistêmica; Profilaxia TV- Profilaxia para prevenção transmissão vertical do HIV; DAC - Doença Cardíaca; DGC - Doença Gastrointestinal Crônica; LES - Lupus eritematoso sistêmico; HC - Hipotireoidismo congênito; AF - Anemia Falciforme. 
Quadro 3. Caracterização dos trabalhos realizados no Brasil sobre adesão à medicação.

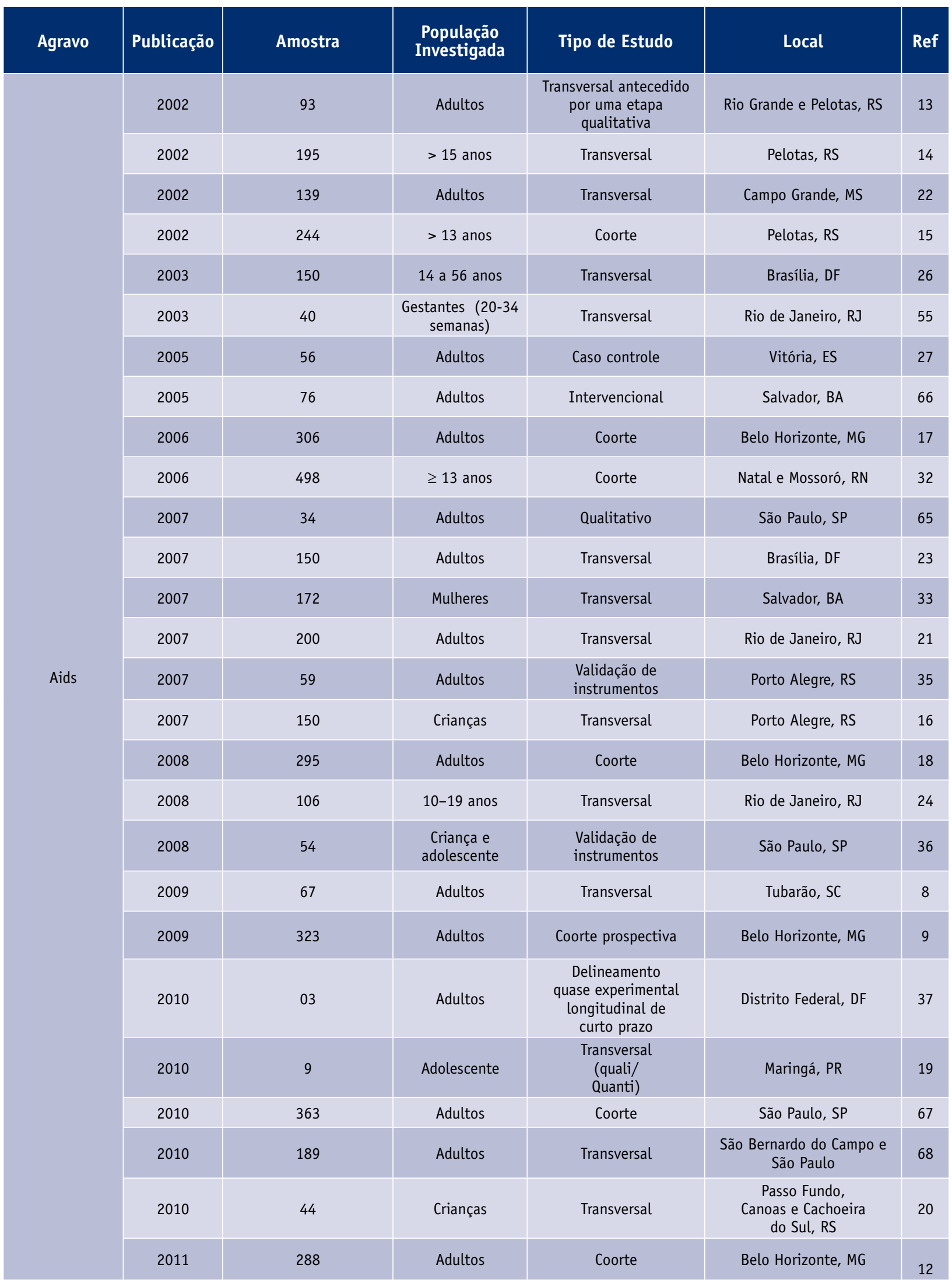


Quadro 3 (cont): Caracterização dos trabalhos realizados no Brasil sobre adesão à medicação.

\begin{tabular}{|c|c|c|c|c|c|c|}
\hline Agravo & Publicação & Amostra & $\begin{array}{l}\text { População } \\
\text { Investigada }\end{array}$ & Tipo de Estudo & Local & Ref \\
\hline \multirow{9}{*}{ Tuberculose } & 2000 & 196 & Todos * & Transversal & Campinas, SP & 69 \\
\hline & 2002 & 341 & Todos * & Coorte & Goiânia, G0 & 54 \\
\hline & 2005 & 436 & Todos * & Coorte & Campinas, SP & 34 \\
\hline & 2007 & 610 & Adultos & Coorte & Rio Grande do Sul, RS & 38 \\
\hline & 2008 & 98 & Adultos & Coorte & Vitória, ES & 56 \\
\hline & 2009 & 395 & $>15$ anos & Coorte & Vitória, ES & 70 \\
\hline & 2009 & 1534 & Todos * & $\begin{array}{l}\text { Ecológico, transversal } \\
\text { e descritivo }\end{array}$ & Salvador, BA & 76 \\
\hline & 2009 & 142 & $\geq 15$ anos & Transversal & Duque de Caxias, RJ & 75 \\
\hline & 2011 & 360 & 4-84 anos & Coorte histórica & Carapicuíba, SP & 77 \\
\hline \multirow{8}{*}{ HAS } & 2004 & 200 & Adultos & Transversal & São Paulo, SP & 59 \\
\hline & 2004 & 1699 & Adultos & Transversal & Rio de Janeiro, SP & 71 \\
\hline & 2007 & 462 & Adultos & Transversal & São Luiz, MA & 64 \\
\hline & 2008 & 210 & Todos * & Transversal & Rio de Janeiro, RJ & 39 \\
\hline & 2008 & 46 & Todos * & $\begin{array}{l}\text { Validação de } \\
\text { instrumento }\end{array}$ & Blumenau, SC & 40 \\
\hline & 2010 & 109 & Adultos e idosos & Transversal & Ribeirão Preto, SP & 41 \\
\hline & 2010 & 595 & Todos * & Transversal & Blumenau, SC & 42 \\
\hline & 2011 & 440 & Adultos & Transversal & São Paulo, SP & 60 \\
\hline \multirow{2}{*}{$\mathrm{DAC}$} & 1996 & 485 & Adultos e idosos & Transversal & São Paulo, SP & 61 \\
\hline & 2010 & 120 & Adultos & Coorte & Porto Alegre, RS & 57 \\
\hline esquizofrenia & 2005 & 50 & Adultos & Coorte & São Paulo, SP & 5 \\
\hline $\mathrm{DGC}$ & 2006 & 110 & Adultos & Transversal & Ribeirão Preto, SP & 62 \\
\hline \multirow{2}{*}{ Asma } & 2007 & 77 & Adultos & Coorte & Ribeirão Preto, SP & 73 \\
\hline & 2008 & 160 & Adultos & Coorte & Salvador, BA & 29 \\
\hline $\begin{array}{c}\text { Esquizofrenia e } \\
\text { outras doenças } \\
\text { psicóticas }\end{array}$ & 2007 & 109 & $18-65$ anos & Transversal & Amparo e Itapira, SP & 44 \\
\hline $\mathrm{AF}$ & 2008 & 108 & Crianças & Coorte & Belo Horizonte, MG & 30 \\
\hline Câncer & 2008 & 61 & Adulto & Exploratório & São Paulo, SP & 46 \\
\hline \multirow{2}{*}{$\begin{array}{l}\text { Insuficiência } \\
\text { cardíaca }\end{array}$} & 2008 & 50 & Adultos & Transversal & Rio de Janeiro, RJ & 72 \\
\hline & 2010 & 252 & Adultos & Transversal & Porto Alegre, RS & 43 \\
\hline \multirow{2}{*}{ Diversas } & 2009 & 377 & idosos & Transversal & Belo Horizonte, MG & 31 \\
\hline & 2010 & 120 & Idosos & Transversal & Salto Grande, SP & 50 \\
\hline EMJ & 2009 & 43 & $15-66$ anos & Transversal & São Paulo, SP & 49 \\
\hline
\end{tabular}


Quadro 3 (cont): Caracterização dos trabalhos realizados no Brasil sobre adesão à medicação.

\begin{tabular}{|c|c|c|c|c|c|c|}
\hline Agravo & Publicação & Amostra & $\begin{array}{l}\text { População } \\
\text { Investigada }\end{array}$ & Tipo de Estudo & Local & Ref \\
\hline \multirow{3}{*}{ Diabetes } & 2009 & 46 & Adultos & Transversal & Ribeirão Preto, SP & 47 \\
\hline & 2010 & 79 & Adultos & Transversal & Sobral, CE & 48 \\
\hline & 2009 & 22 & $>40$ anos & Transversal & Cabedelo, PB & 63 \\
\hline $\begin{array}{l}\text { Doença de } \\
\text { crohn }\end{array}$ & 2009 & 100 & Adultos & Transversal & São Paulo, SP & 45 \\
\hline LES & 2009 & 246 & Mulheres & Transversal & Rio de Janeiro, RJ & 51 \\
\hline $\begin{array}{l}\text { Hipertensão/ } \\
\text { diabetes }\end{array}$ & 2009 & 50 & Adultos & Transversal & $\begin{array}{c}\text { Jaboatão dos Guararapes, } \\
\text { PE }\end{array}$ & 25 \\
\hline Alcoolismo & 2010 & 316 & Adultos & Transversal & Campo Grande, MS & 74 \\
\hline $\mathrm{HC}$ & 2010 & $\begin{array}{l}50 \text { (acompanhantes } \\
\text { de crianças) }\end{array}$ & Adultos & Coorte & Belém do Pará, PA & 52 \\
\hline Febre reumática & 2010 & 536 & $\begin{array}{l}\text { Criança e } \\
\text { adolescente }\end{array}$ & Transversal & Rio de Janeiro, R J & 58 \\
\hline
\end{tabular}

HAS - Hipertensão Arterial Sistêmica; DAC - Doença Cardíaca; DGC - Doença Gastrointestinal Crônica; LES - Lupus eritematoso sistêmico; $\mathrm{HC}$ - Hipotireoidismo congênito; AF - Anemia Falciforme; EMJ - Epilepsia mioclônica juvenil

\section{REFERÊNCIAS}

1. OMS. Adherence to long-term therapies: Policy for Action. Meeting Report 4-5 June 2001. Geneva: World Health Organization; 2001.

2. Silveira LMC, Ribeiro VMB. Grupo de Adesão ao tratamento: espaço de ensinagem para profissionais de saúde e pacientes. Interface - Comun, Saude Educ, 2004-2005. (9):91-4.

3. Sabaté E. Adherence to long-term therapies: evidence for action. Geneva: World Health Organization; 2003.

4. Reiners AAO, Azevedo RCSA, Vieira MAV, Arruda ALG. Produção bibliográfica sobre adesão/não-adesão de pessoas ao tratamento de saúde. Cienc Saude Colet, 2008. 13(Suppl 2):2299306.

5. Rosa MA, Elkis H. Adesão em Esquizofrenia. Rev Psiq Clín 2007; 34(Suppl 2):189-92.

6. Oigman W. Métodos de avaliação da adesão ao tratamento anti-hipertensivo. Rev Bras Hipertens, 2006. 13(1):30-4.

7. Polejack L, Seidl EMF. Monitoramento e avaliação da adesão ao tratamento antirretroviral para HIV/aids: desafios e possibilidades. Cienc Saude Colet, 2010. 15(Suppl 1):1201-8.

8. Blatt CR, Citadin CB, de Souza FG, Melo RS, Galato D. Avaliação da adesão aos anti-retrovirais em um município no Sul do Brasil. Rev Soc Bras Med Trop, 2009. 42(2):131-6.

9. Gomes RRFM, Machado CJ, Acurcio FA, Guimarães MDC. Utilização dos registros de dispensação da farmácia como indicador da não-adesão à terapia anti-retroviral em indivíduos infectados pelo HIV. Cad Saude Publica, 2009. 25(3):495-506.

10. 1Haynes RB, Taylor DW, Sackett DL, Gibson ES, Bernholz CD, Mukherjee J. Can simple clinical measurements detect patient non-compliance? Hipertension, 1980. (2)6:757-64.
11. Forgaty L, Roter D, Larson S, Burke J, Gillespie J, Levy R. Patient adherence to HIV medication regimens: a review of published and abstract reports. Patient Educ Couns, 2002. (46):93-108.

12. Rocha GM, Machado CJ, Acurcio FA; Guimarães MDC. Monitoramento da adesão ao tratamento antirretroviral no Brasil: um urgente desafio. Cad Saude Publica, 2011. 27(1):67-78.

13. Leite JCC, Drachler ML, Centeno MO, Pinheiro CAT, Silveira VL. Desenvolvimento de uma escala de auto-eficácia para adesão ao tratamento anti-retroviral. Psicol Reflex Crit, 2002. 15(1):121-33.

14. Pinheiro CAT, de-Carvalho-Leite JC, Drachler ML, Silveira VL. Factors associated with adherence to antiretroviral therapy in HIV/AIDS patients: a cross-sectional study in Southern Brazil. Braz J Med Biol Res, 2002. 35(10):1173-81.

15. Silveira MPT, Draschler ML, Leite JCC, Pinheiro CAT, Silveira VL. Predictors of undetectable plasma viral load in HIV-positive adults receiving antiretroviral therapy in Southern Brazil. Braz J Infect Dis, 2002. 6(4):164-71.

16. Wachhol NIR, Ferreira J. Adherence to antiretroviral therapy in children: a study of prevalence and associated factors. Cad Saude Publica, 2007. 23(3):424-34.

17. Acurcio FA, Puig-Junoy J, Bonolo PF, Braga CMG, Guimarães MDC. Análisis coste-efectividad de la adhesión inicial a la terapia antirretroviral entre individuos infectados por el VIH en Belo Horizonte, Brasil. Rev Esp Salud Publica, 2006. 80(1):41-54.

18. Bonolo PF, Machado CJ, César CC, Ceccato MGB, Guimarães MDC. Vulnerabilidade e não-adesão à terapia antirretroviral. Cad Saude Publica, 2008. 24(11):2603-13.

19. Guerra CPP, Seidl EMF. Adesão em HIV/AIDS: estudo com adolescentes e seus cuidadores primários. Psicol Estud, 2010. 15(4):781-9. 
20. Trombini ES, Schermann LB. Prevalência e fatores associados à adesão de crianças na terapia antirretroviral em três centros urbanos do sul do Brasil. Cienc Saude Colet, 2010. 15(2):419-425.

21. Remien RH, Bastos FI, Terto VJNR, Raxach JC, Pinto RM, Parker RG, et al. Adherence to antiretroviral therapy in a contexto $\mathrm{f}$ universal Access, in Rio de Janeiro. AIDS Car, 2007.19(6):740-8.

22. Monreal MTFD, Cunha RV, Trinca LA. Compliance to antiretroviral medication as reported by AIDS patients assisted at the University Hospital of the Federal University of Mato Grosso do Sul. Braz J Infect Dis, 2002. 6(1):8-14.

23. Carvalho CV, Merchán-Hamann E, Matsushita R. Determinantes da adesão ao tratamento anti-retroviral em Brasília, DF: um estudo de caso-controle. Rev Soc Bras Med Trop, 2007. 40(5):55565 .

24. Filho LFB, Nogueira SA, Machado ES, Abreu TF, Oliveira RH, Evangelista L, Hofer CB. Factors associated with lack of antiretroviral adherence among adolescents in a reference centre in Rio de Janeiro, Brazil. Int J STD AIDS, 2008. 19(10):685-8.

25. Bezerra DS, Silva AS, Carvalho ALM. Avaliação das características dos usuários com hipertensão arterial e/ou diabetes mellitus em uma Unidade de Saúde Pública, no município de Jaboatão dos Guararapes-PE, BRASIL. Rev Cienc Farm Basica Apl, 2009. 30(1):69-73.

26. Carvalho CV, Duarte DB, Merchán-Hamann E, Bicudo E, Laguardia J. Determinantes da aderência à terapia anti-retroviral combinada em Brasília, Distrito Federal, Brasil, 1999-2000. Cad Saude Publica, 2003. 19(2):593-604.

27. Gupta N, Silva ACS, Passos LN. O papel da assistência domiciliar integrada na adesão do paciente à terapia anti-retroviral. Rev Soc Bras Med Trop, 2005. 38(3):241-5.

28. Rosa MA, Marcolin MA, Elkis H. Avaliação dos fatores de aderência ao tratamento. Rev Bras Psiquiatr, 2005. 27(3):178-84.

29. Santos PM, D’Oliveira Júnior A, Noblat LACB, Machado AS, Noblat ACB, Cruz AA. Preditores da adesão ao tratamento em pacientes com asma grave atendidos em um centro de referência na Bahia. J Bras Pneumol, 2008. 34(12):995-1002.

30. Bitarães EL, Oliveira BM, Viana MB. Compliance with antibiotic prophylaxis in children with sickle cell anemia: a prospective study. J Pediatr, 2008. 84(4):316-22.

31. Acurcio FA, Silva AL, Ribeiro AQ, Rocha NP, Silveira MR et al. Complexidade do regime terapêutico prescrito para idosos, Belo Horizonte, MG. Rev Assoc Med Bras, 2009. 55(4):468-74.

32. Brito AM, Szwarcwa CL, Castilho EA. Fatores associados à interrupção de tratamento anti-retroviral. Rev Assoc Med Bras, 2006. 52(2):86-92.

33. Diniz NMF, Almeida LCG, Ribeiro BCS, Macêdo VG. Mulheres vítimas de violência sexual: adesão à quimioprofilaxia do HIV. Rev Latino Am Enfermagem, 2007. 15(1):7-12.

34. Oliveira HB, Marin-León L, Gardinali J. Análise do programa de controle da tuberculose em relação ao tratamento, em Campinas - SP. J Bras Pneumol, 2005. 31(2):133-8.

35. Remor E, Milner-Moskovics J, Preussler G. Adaptação brasileira do "Cuestionario para la Evaluación de la Adhesión al Tratamiento Antiretroviral. Cad Saude Publica, 2007. 41(5):685-94.

36. Costa LS, Latorre MRDO, Silva MH, Bertolini DV, Machado DM, Pimentel SR, et al.Validação e reprodutibilidade de uma escala de auto-eficácia para adesão ao tratamento anti-retroviral em pais ou cuidadores de crianças e adolescentes vivendo com HIV/ AIDS. J Pediatr, 2008. 84(1):41-6.

37. Faustino QM, Seidl EMF. Intervenção Cognitivo-Comportamental e Adesão ao Tratamento em Pessoas com HIV/Aids. Psic: Teor e Pesq, 2010. 26(1):121-30.
38. Picon PD, Bassanesi SL, Caramori MLA, Ferreira RLT, Jarczewski CA, Vieira PRB. Fatores de risco para a recidiva da tuberculose. J Bras Pneumol, 2007. 33(5):572-8.

39. Bloch KV, Melo NA, Nogueira AR. Prevalência da adesão ao tratamento anti-hipertensivo em hipertensos resistentes e validação de três métodos indiretos de avaliação da adesão. Cad Saude Publica, 2008. 24(12): 2979-84.

40. Santa-Helena ET, Tiaraju E, Nemes, MIB, Eluf-Neto J. Desenvolvimento e validação de questionário multidimensional para medir não-adesão ao tratamento com medicamentos. Rev Saude Publica, 2008. 42(4):764-67.

41. Ungari AQ, Fabbro ALD. Adherence to drug treatment in hypertensive patients on the Family Health Program. Braz J Pharm Sci, 2010. 46(4):811-8.

42. Santa-Helena ET, Nemes MIB, Neto JE. Fatores associados à não-adesão ao tratamento com anti-hipertensivo em pessoas atendidas em unidades de saúde da família. Cad. Saúde, 2010. 26(12): 2389-98.

43. Castro RA, Aliti GB, LInhares JC, Rabelo ER. Adesão ao tratamento de pacientes com insuficiência cardíaca em um hospital universitário. Rev Gaucha Enferm, 2010. 31(2):225-31.

44. Dantas CR, Banzato CEM. Inter-rater reliability and factor analysis of the Brazilian version of the Schedule for the Assessment of Insight: Expanded Version (SAI-E). Rev Bras Psiquiatr, 2007. 29(4):359-62.

45. Cornelio RC, Pinto AL, Pace FH, Moraes JP, Chebli JM. Nonadherence to the therapy in Crohn's disease patients: prevalence and risk factors. Arq Gastroenterol, 2009. 46(3):183-9.

46. 46 Marques PAC, Pierin AMG. Fatores que influenciam a adesão de pacientes com câncer à terapia antineoplásica oral. Acta Paul Enferm, 2008. 21(2):323-9.

47. Gimenes HT, Zanetti ML, Haas VJ. Fatores relacionados à adesão do paciente diabético à terapêutica medicamentosa. Rev Latino Am Enfermagem, 2009. 17(1):46-51.

48. Araújo MFM, Gonçalves TC, Damasceno MMC, Caetano JA. Adesão de diabéticos ao tratamento medicamentoso. Esc Anna Nery Rev Enferm, 2010. 14 (2):361-7.

49. Martins HH, Alonso NB, Guilhoto LMFF, Guaranha MSB, Yacubian EMT. Adherence to treatment in patients with juvenile myoclonic epilepsy: correlation with quality of life and adverse effects of medication. J epilepsy clin neurophysiol, 2009. 15(4):192-6.

50. Obreli-Neto PR, Prado MF, Vieira JC, Fachini FC, Pelloso SM, Marcon SS, et al. Fatores interferentes na taxa de adesão à farmacoterapia em idosos atendidos na rede pública de saúde do Município de Salto Grande ? SP, Brasil. Rev Cienc Farm Basica Apl, 2010. 31(3):229-33.

51. Santos MO. Avaliação da adesão à terapêutica medicamentosa em pacientes com Lúpus Eritematoso Sistêmico atendidos em Hospital Universitário na cidade do Rio de Janeiro, Brasil [tese]. Rio de Janeiro:Escola Nacional de Saúde Pública Sérgio Arouca. 2009.

52. Oliveira FPS, Ferreira EAP. Adesão ao Tratamento do Hipotireoidismo Congênito Segundo Relato de Cuidadores. Psicol Reflex Critm, 2010. 23(1):19-28.

53. Carvalho ARS, Dantas RAS, Pelegrino FM, Corbi ISA. Adaptação e validação de uma medida de adesão à terapia de anticoagulação oral. Rev. Latino am Enferm, 2010. 18(3):301-8.

54. Rabahi MF, Rodrigues AB, Mello FQ, Netto JCA, Kritski AL. Noncompliance with tuberculosis treatment by patients at a tuberculosis and AIDS reference hospital in midwestern Brazil. J Infect Dis, 2002. 6:63-73. 
55. Lambert JS, Nogueira AS, Abreu T, Machado ES, Costa TP, Bondarovsky $\mathrm{M}$, et al. A pilot study to evaluate the safety and feasibility of the administration of AZT/3TC fixed dose combination to HIV infected pregnant women and their infants in Rio de Janeiro, Brazil. Sex Transm Infect, 2003. 79(6):448-52.

56. Maciel ELN, Silva AP, Meireles W, Fiorotti K, Hadad DJ, Dietze $R$. Tratamento supervisionado em pacientes portadores de tuberculose utilizando supervisores domiciliares em Vitória, Brasil. J Bras Pneumol, 2008. 34(7):506-13.

57. Silveira LCJ, Souza EN, Goldmeier S, Silva AF, Rabelo ER. Adesão às consultas e ao tratamento medicamentoso de pacientes em ensaios clínicos randomizados da indústria. Rev Gaucha Enferm, 2010. 31(3):423-7.

58. Pelajo CF, Lopez-Benitez JM, Torres JM, Oliveira SK. Adherence to secondary prophylaxis and disease recurrence in 536 Brazilian children with rheumatic fever. Pediatr Rheumatol, 2010. 22(8):1-5.

59. Sanchez CG, Pierin AMG, Mion Júnior D. Comparação dos perfis dos pacientes hipertensos atendidos em Pronto-Socorro e em tratamento ambulatorial. Rev Esc Enferm, 2004. 38(1): 90-8.

60. Pierin AMG, Marroni SN, Taveira Luzi AF, Besenñor IJM. Controle da hipertensão arterial e fatores associados na atenção primária em unidades básicas de saúde localizadas na região oeste da cidade de São Paulo. Cienc Saude Colet, 2011. 16(1):1389400 .

61. Chizzola PR, Mansur AJ, Luz PL, Bellotti G. Compliance with pharmacological treatment in outpatients from a Brazilian cardiology referral center. São Paulo Med J, 1996. 114(5):1259-64.

62. Dewulf NLS, Monteiro RA, Passos ADC, Vieira EM, Troncon LEA. Adesão ao tratamento medicamentoso em pacientes com doenças gastrintestinais crônicas acompanhados no ambulatório de um hospital universitário. Rev Bras Cienc Farm, 2006. 42(4):575-84.

63. Morais GFC, Soares MJGO, Costa MML, Santos IBC. O diabético diante do tratamento, fatores de risco e complicações crônicas. Rev. Enferm, 2009. 17(2): 240-5.

64. Mochel EG, Andrade CF, Almeida DS, Tobias AF, Cabral R, Cossettid RD. Avaliação do tratamento e controle da hipertensão arterial sistêmica em pacientes da rede pública em São Luis (MA). Rev Bahiana Saude Publica, 2007. 31(1):90-101.

65. Melchior R, Nemes MIB, Alencar TMD, Buchalla CM. Desafios da adesão ao tratamento de pessoas vivendo com HIV/Aids no Brasil. Cad Saude Publica, 2007. 41(Supl 2):87-93.

66. Garcia R, Pondé M, Lima MSAR, Stolze SMO, Badaró R. Lack of effect of motivation on the adherence of HIV-positive/AIDS patients to antiretroviral treatment. Braz J Infect Dis, 2005. 9(6):494-9.

67. Cáritas RB. Avaliação da efetividade de uma intervenção psicossocial para melhorar a adesão do paciente à terapia antirretroviral da AIDS: ensaio controlado aleatório utilizando monitoramento eletrônico [tese]. São Paulo:Faculdade de Medicina de São Paulo. 2010 .

68. Mendes-Corrêa MC, Martins LG, Tenore S, Leite OH, Leite AG, Cavalcante AJW et al . Barriers to treatment of hepatitis $C$ in HIV/HCV coinfected adults in Brazil. Braz J Infect Dis, 2010. 14(3): 237-241.

69. Oliveira HB, Djalma CMF. Abandono de tratamento e recidiva da tuberculose: aspectos de episódios prévios, Campinas, SP, Brasil, 1993-1994. Cad Saude Publica, 2000. 34 (5):437-43.
70. Maciel ELN, Brioschi AP, Guidoni LM, Cerqueira ACB, Prado $\mathrm{TN}$, Fregona $\mathrm{G}$ et al. Fatores associados ao abandono da quimioprofilaxia de TB no município de Vitória (ES): um estudo de coorte histórica. J Bras Pneumol, 2009. 35(9):884-91

71. Muxfeldt ES, Nogueira AR, Salles GF, Bloch KV. Demographic and clinical characteristics of hypertensive patients in the internal medicine outpatient clinic of a university hospital in Rio de Janeiro. Med J, 2004. 122(3):87-93.

72. Corrêa LA, Santos I, Albuquerque DC. Consulta de enfermagem: Pesquisar/Cuidar através da escuta sensível em uma clínica de insuficiência cardíaca/ Consulta de enfermería: Investigar. Online braz j nurs, 2008. 7(1).

73. Araujo ACS, Ferraz E, Borges MC, Terra Filho J, Vianna EO. Investigação de fatores associados à asma de difícil controle. $\mathrm{J}$ Bras Pneumol, 2007. 33(5):495-501.

74. Peixoto C, Prado CHO, Rodrigues CP, Cheda JND, Mota LBT, Veras AB. Impacto do perfil clínico e sociodemográfico na adesão ao tratamento de pacientes de um Centro de Atenção Psicossocial a Usuários de Álcool e Drogas (CAPSad). J Bras Psiquiatr, 2010. 59(4):317-21

75. Cantalice F, Paulo J. Efeito do incentivo alimentício sobre o desfecho do tratamento de pacientes com tuberculose em uma unidade primária de saúde no município de Duque de Caxias, Rio de Janeiro. J Bras Pneumol, 2009. 35(10):992-97.

76. Souza MSPL, Pereira Susan Martins, Marinho JM, Barreto ML. Características dos serviços de saúde associadas à adesão ao tratamento de tuberculose. Rev Saude Publica, 2009. 43(6):9981005.

77. Vieira AA, Ribeiro SA. Adesão ao tratamento da tuberculose após a instituição da estratégia de tratamento supervisionado no município de Carapicuíba, Grande São Paulo. J Bras Pneumol, 2011. 37(2):223-31

78. Mellins CA, Cott EB, Dolezal C, Abrams EJ. The role of psychosocial and family factors in adherence to antiretroviral treatment in human immunodeficiency virus-infected children. Pediatr Infect Dis, 2004. 23(11):1035-41.

79. Morisky DE, Green LW, Levine DM. Concurrent and predictive validity of a self-reported measure of medication adherence. Med Care, 1986. 24(1):67-74

80. Morisky DE, DiMatteo MR. Improving the measurement of selfreported medication nonadherence: Response to Authors. Clin Epidemiol, 2011. 64:255-7.

81. Ben AJ, Neumann CR, Mengue SS. Teste de Morisky-Green e Brief medication Questionnarie para avaliar a adesão a medicamentos. Rev Saude Publica, 2012. 6(2): 279-289.

82. Strelec MAAM, Pierin AMG, Mion Júnior D. A influência do conhecimento sobre a doença e a atitude frente à tomada dos remédios no controle da hipertensão arterial. Arq Bras Cardiol, 2003. 81(4):343-54.

83. BRASIL. Manual de Recomendações para o Controle da Tuberculose no Brasil.Ministério da Saúde. Secretaria de Vigilância em Saúde. Programa Nacional de Controle da Tuberculose. 2010.

84. BRASIL. Portaria ${ }^{\circ}$ 3.916/MS/GM de 30 de Outubro de 1998. Estabelece a Política Nacional de Medicamentos. Diário Oficial da União 1998; 10 nov. 